\title{
Benedito Nunes, leitor de Foucault: entre as palavras e as coisas, entre Belém e Paris
}

\author{
Benedito Nunes, reader of Foucault: between words and \\ things, between Belém and Paris
}

\author{
Ernani Chaves \\ https://orcid.org/0000-0002-8988-1910 - E-mail: ernanic6057@gmail.com
}

\section{RESUMO}

Ao precisar sair do Brasil por problemas com o regime militar, Benedito Nunes chegou em Paris em 1967, um ano depois da publicação de As palavras e as coisas, ou seja, em plena onda estruturalista. O objetivo deste artigo é mostrar o impacto do livro de Foucault sobre Benedito Nunes, cujo resultado imediato foi a publicação, em 1968, da primeira resenha sobre o livro publicada no Brasil. Além disso, pretendo não apenas reconstituir os argumentos mais importantes dessa leitura mas também, ao mesmo tempo, compreender sua importância e sua originalidade, por contraste com a interpretação de Roberto Machado. O pano de fundo, memorialístico, é o Brasil da ditadura militar e do jovem aluno de Benedito Nunes, autor desse artigo.

Palavras-chave: Arqueologia. Ciências humanas. Linguagem.

\begin{abstract}
When he needed to leave Brazil due to problems with the military regime, Benedito Nunes arrived in Paris in 1967, a year after the publication of The Order of Things, that is, in the middle of a structuralist wave. The purpose of this article is to show the impact of Foucault's book on Benedito Nunes, whose immediate result was the publication, in 1968, of the first review of the book published in Brazil. Furthermore, I intend not only to reconstitute the most important ar-
\end{abstract}


guments of this reading but also, at the same time, to understand its importance and its originality, in contrast to Roberto Machado's interpretation. The backdrop is the Brazil of the military dictatorship and the memories of the young student of Benedito Nunes, author of this article

Keywords: Archeology. Human sciences. Language.

Aquele que lê a "Cronologia" estabelecida nos Dits et écrits, de Michel Foucault, verá que ele visitou Belém duas vezes: em junho de 1973 e em novembro de 1976. Na primeira vez, como turista, logo depois das conferências $A$ verdade e as formas jurídicas, proferidas na Pontifícia Universidade Católica do Rio de Janeiro, no final de maio de 1973. Antes de Belém, ele passara por Belo Horizonte e outras cidades de Minas Gerais até chegar a Amazônia, indo primeiro a Manaus. A segunda, cumprindo uma promessa feita a Benedito Nunes nessa primeira viagem de 1973, de que voltaria a Belém para fazer conferências. Esse primeiro encontro se deu na casa de Machado Coelho, influente intelectual paraense, na ocasião Cônsul Honorário da França em Belém. Foucault cumpriu sua promessa. Assim, quando em 1976, ele organizou sua viagem ao Brasil, sob a coordenação da Alliance Française, pediu que Belém fosse incluída no roteiro. Desse modo, nos dias 6, 7 e 8 de novembro daquele ano, ele falou em francês, para um público seleto, no Auditório do então Centro de Letras e Artes da UFPA. Benedito Nunes foi o mediador durante o debate, servindo de tradutor. Creio que Foucault aceitou o convite de Benedito Nunes não apenas pela possibilidade de rever uma cidade que o havia agradado bastante durante a primeira visita, mas também por ter ficado impressionado em encontrar em Belém, no norte do Brasil, alguém que não só conhecia a sua obra, mas também que já havia escrito sobre As palavras e as coisas.

De uma forma muito especial e significativa, os caminhos de Foucault e Benedito Nunes se cruzaram antes de 1973, antes do primeiro encontro pessoal deles. Além de professor na Faculdade de Filosofia, Nunes era envolvido com o teatro desde o final da década de 1950 e foi Coordenador da Escola de Teatro da UFPA entre 1962 e os começos de 1967, ou seja, já em plena ditadura militar brasileira.

Foi como diretor da Escola de Teatro que Nunes começou a sofrer, como ele mesmo conta em uma anotação de seu diário, datada de 3 de janeiro de 1967, "perseguições políticas" as quais, inclusive, o estavam impedindo de sair do país, uma vez que não estava conseguindo obter um passaporte (CHAVES, 2011, p. 42). Além disso, sofria um processo na esfera da Justiça Militar. Certamente, "sair do país", naquela época, era uma das opções dos intelectuais brasileiros para escapar da prisão e Benedito Nunes começou então a projetar viajar para a França, a fim de realizar em Paris, seu Doutoramento. Nessa mesma anotação do começo de 1967, ele se referiu àquela época como se ela estivesse sob o domínio do "espírito de gravidade" do Zaratustra, de Nietzsche. Da secção "De velhas e novas tábuas", da terceira parte desse livro, ele anota a seguinte passagem:"...e consideraremos como falsa toda verdade que não venha acompanhada de risos". Uma época triste, de perseguições a todos os que eram considerados inimigos do regime e, em breve, de institucionalização da tortura, nada produz a não ser "verdades falsas".

Após longa negociação entre a Reitoria da UFPA e os órgãos de segurança, Benedito Nunes e sua esposa Maria Sylvia conseguem viajar e chegam a Paris, em outubro de 1967, ele, com o intuito de escrever uma Tese de Doutoramento sobre o Modernismo brasileiro, no Instituto de Estudos Portugueses e Brasileiros da Sorbonne. Ou seja, o casal Nunes chegou em Paris às portas do maio de 1968 e um pouco depois de outro acontecimento, que abalou a cena 
filosófica e intelectual francesa: um ano e meio antes desse outubro de 1967, em abril de 1966 mais exatamente, é publicado em Paris, As palavras e as coisas. Em 10 de agosto de 1966, uma matéria no Le Nouvel Observateur dedicada a venda de livros no verão daquele ano, tem como título "Foucault comme des petits pains", se referindo ao sucesso inesperado do livro em alusão à presença cotidiana do pão na culinária francesa.

Os três mil e quinhentos exemplares da edição de abril se esgotaram rapidamente; em junho, uma reimpressão de cinco mil, em julho mais três mil, em setembro, mais três mil e quinhentos, conforme registra Didier Eribon em sua biografia de Foucault (ERIBON, 2011, p. 266). O sucesso continuou em 1967: quatro mil em março e mais cinco mil em novembro. Poderíamos imaginar a cena (trata-se apenas de imaginação): Benedito Nunes saindo para comprar "pãezinhos" e voltando com um exemplar de As palavras e as coisas! Em resumo: Benedito Nunes chega a Paris não apenas às vésperas do maio de 1968, mas também em meio ao estrondoso sucesso do livro de Foucault e da onda estruturalista.

Em 1988, na "Apresentação" que escreveu ao meu livro Foucault e a psicanálise, Benedito Nunes referiu-se à "rara beleza verbal" de Les mots e les choses! (CHAVES, 1988, p. XI). Certamente foi essa beleza que o atraiu, de início, para a intensa leitura do livro, tantas eram as marcas de leitura contidas no seu exemplar pessoal, que manuseei diversas vezes na sua biblioteca. Mas, mais que a beleza do estilo de Foucault, o que Benedito Nunes encontrava a cada página do livro era a presença de outro pensamento, ele reconhecia na arquitetura central do livro o toque decisivo do filósofo que ele já havia escolhido como referência maior de sua própria perspectiva filosófica: Martin Heidegger.

Benedito Nunes voltou ao Brasil em 1969, sem ter concluído o seu doutoramento. Entretanto, foi ainda na temporada parisiense, que ele escreveu um artigo intitulado "A arqueologia da arqueologia", no qual jogando Foucault contra ele mesmo, procurava mostrar que era preciso fazer uma "arqueologia" da perspectiva de Foucault, o que nos levaria, de todo modo, a Heidegger. Dessa perspectiva, a referência maior, segundo Nunes, para o projeto de uma arqueologia das ciências humanas seria o modo pelo qual Heidegger teria compreendido o processo de formação e desenvolvimento do pensamento ocidental. Esse artigo foi publicado em quatro partes, entre outubro e novembro de 1968, no "Suplemento Literário" do jornal O Estado de São Paulo, para quem Benedito Nunes colaborava já há algum tempo. Trata-se, portanto, de artigo pioneiro na recepção brasileira de As palavras e as coisas, e que foi logo em seguida incluído na primeira edição de $O$ dorso do tigre, um conjunto de ensaios de Benedito Nunes, publicado em 1969, pela Editora Perspectiva.

O dorso do tigre desde o título e da epígrafe carrega as marcas da leitura de As palavrase as Coisas: "...não deveria ser lembrado que estamos presos ao dorso de um tigre?", a epígrafe, retoma as mesmas palavras de Foucault ao final da secção IV, do capítulo IX do livro. ${ }^{1}$ Essa interrogação arremata uma problemática central da arqueologia das ciências humanas, que Foucault empreendera naquele momento, qual seja, a consideração do homem no interior da "analítica da finitude" própria ao século XIX e que na esteira de Kant leva à conclusão de que o homem seria um "estranho duplo empírico-transcendental": "O homem -escreve Foucault - na analítica da finitude, é um estranho duplo empírico-transcendental, porquanto é um ser tal que nele se tomará conhecimento do que torna possível todo conhecimento" (FOUCAULT, 1981, p. 334).

\footnotetext{
' Na verdade, a expressão "dorso do tigre" é retirada por Foucault do texto de Nietzsche "Verdade e mentira no sentido extramoral", num contexto muito interessante e significativo no interior da argumentação de Foucault acerca do lugar da linguagem entre as ciências empíricas. Em 1973, na $1^{\text {a }}$ conferência de $A$ verdade e as formas jurídicas Foucault retoma esse texto de Nietzsche (FOUCAULT, 2002, p. 13-14).
} 
O aparecimento das "ciências empíricas" no século XIX - a biologia, a economia e a linguística - modifica radicalmente a "episteme" da representação vigente na Idade Clássica (séculos XVII e XVIII). É apenas assim, que poderíamos compreender o aparecimento das chamadas "ciências humanas", nas quais o sujeito e o objeto são os mesmos, isto é, o homem.

A presença de Kant no livro de Foucault não escapa a Benedito Nunes, que começa o artigo comparando o empreendimento de Foucault - o de fazer uma "arqueologia das ciências humanas" - com o de Kant na Crítica da razão pura, que teria feito uma "arqueologia das ciências da natureza". Para tal, Benedito Nunes parte da concepção foucaultiana de "positividade", que é bem diferente, entretanto, da acepção kantiana, pois se apresenta como contrária ao tipo de historiografia própria de uma história das ideias e que "repousa numa secreta sedimentação histórico-filosófica", que ele, Benedito Nunes, vai "procurar identificar". Ora, essa espécie de segredo, que a "arqueologia da arqueologia" pretende revelar, acabaria trazendo à luz a importância crucial do pensamento de Heidegger, cuja ontologia é considerada a "matriz geradora da arqueologia de Foucault". Tal referência não se contrapõe àquela que ele fizera a Kant no começo do artigo. Muito pelo contrário, Benedito Nunes se refere ao fato de que o Kant de Foucault em As palavras e as coisas era o Kant de Heidegger, em especial o do artigo "Kant e o problema da Metafísica", relação absolutamente confirmada pelos estudos foucaultianos posteriores. No Prefácio à $1^{\text {a }}$ edição desse texto, de 1929, o próprio Heidegger o considera como uma espécie de explicitação e complemento necessário à mesma problemática, tal como fora trabalhada em "Ser e Tempo". Logo no começo da "Introdução", Heidegger reitera sua afirmação ao dizer: "A seguinte investigação se propõe a tarefa de interpretar a Crítica da razão pura de Kant como uma fundamentação da metafísica. O problema da metafísica é enfocado pois como o problema de uma ontologia fundamental" (HEIDEGGER, 1996, p. 11).

Neste diapasão, Roberto Machado faz um comentário esclarecedor, a respeito dessa mesma questão: é Kant e não Descartes o limiar da modernidade para Foucault (MACHADO, 2000, p. 93). Com Kant, continua Machado, a "crítica" inaugura uma nova concepção de filosofia, segundo a qual se procura explicar "a possibilidade de conhecer os objetos através de uma submissão necessária dos objetos ao sujeito humano". Trata-se, em última instância, de criticar a "filosofia da representação" vigente de Descartes aos Ideólogos do século XVIII, uma filosofia que não é mais uma "análise", mas sim uma "analítica", ou seja, uma reflexão sobre as condições de possibilidade do conhecimento, inclusive sobre as condições de possibilidade da própria representação. É o próprio Foucault quem autoriza essa interpretação:

Por muito diferentes que sejam pela sua forma, seu estilo e seu intento, a questão kantiana e a dos Ideólogos têm o mesmo ponto de partida: a relação das representações entre si. Mas essa relação - o que a funda e a justifica -, Kant não a requer no nível da representação, mesmo atenuada em seu conteúdo até não ser mais, nos confins da passividade e da consciência, do que pura e simples sensação; interroga-a na direção do que a torna possível em sua generalidade. Ao invés de fundar o liame entre as representações por uma espécie de escavação interna que o esvaziasse pouco a pouco até a pura impressão, estabelece-o sobre as condições que definem sua forma universalmente válida" (FOUCAULT, 1981, p. 256-257).

Mas, Foucault não para aí. Ele vai além dessa constatação, que pode parecer inteiramente estabelecida pelos exegetas da Primeira Crítica. E esse além vai Ihe ser dado, justamente, pela intepretação de Heidegger. Pois é Heidegger quem vai destacar a dimensão da "finitude" presente no argumento kantiano - "A finitude do conhecimento humano deve ser buscada, primeiramente, na finitude da intuição que lhe é peculiar" (HEIDEGGER, 1996, p. 31) - e que Roberto Machado sintetiza da seguinte maneira: "Desse modo, a interpretação heideggeriana, que insiste em destacar o papel fundamental da "finitude", da relação entre a es- 
sência do conhecimento e a essência finita do homem mediada por uma intuição própria ao homem, considera a "essência finita do homem" como "um tema principal" da Primeira Crítica (MACHADO, 2000, p. 93).

Daí, poderíamos compreender porque o pensamento de Kant é tão estratégico e tão fundamental para a constituição das ciências humanas, segundo Foucault: é porque com Kant, a modernidade filosófica propriamente dita se instaura, na medida em que nem a filosofia nem a ciência são compreendidas pelos limites da representação; agora, ambas, filosofia e ciência, de maneiras diferentes, escapam da representação e se atribuem duas tarefas muito diferentes, uma vez que enquanto a ciência se ocupa dos objetos e portanto das empiricidades, a filosofia se ocupa do sujeito, do fundamento transcendental do conhecimento, se tornando desse modo uma reflexão sobre a possibilidade de todo conhecimento e, ao mesmo tempo, de uma analítica de tudo o que diz respeito à experiência moderna do homem. Com isso, a Modernidade "inventa" o homem como sujeito e objeto, ao mesmo tempo, de conhecimento. Nas sínteses empíricas, o homem é objeto, é fato. Na analítica transcendental, ao contrário, se torna sujeito, se torna, enfim, "um estranho duplo empírico-transcendental" (FOUCAULT, 1981, p. 334; MACHADO, 1982, p. 71; MACHADO, 2000, p. 94).

Entretanto, já na época um profundo conhecedor do pensamento de Heidegger, Benedito Nunes não hesita em afirmar o quanto As palavras e as coisas é um livro devedor de Heidegger ou mesmo do projeto fenomenológico como um todo, o que não deixa de integrar o pensamento de Husserl, sobre o qual não falaremos aqui, porque isso nos levaria longe demais ${ }^{2}$. É assim, portanto, que a ideia de uma "positividade" da episteme é reconduzida às ideias de "compreensão" e "originário", tão caras ao universo fenomenológico. Sem mais ser um agente do conhecimento para se tornar apenas uma espécie de efeito da episteme, o conhecimento passa a ser considerado como dependente, em cada época, de um processo exterior, estranho à consciência. Segundo Nunes, "à intencionalidade consciente do sujeito sobrepõe-se o apelo do pensamento impessoal, que se infiltra na consciência e lhe impõe uma compreensão preliminar do mundo" (NUNES, 1987, p. 74), como se as verdades científicas estivessem agora dependentes da verdade originária derivada dessa compreensão. Aos conceitos de "compreensão" e "verdade" por sua vez, dever-se-ia acrescentar o de episteme como igualmente devedor do pensamento de Heidegger, embora este o empregue de forma diferente e ao qual poder-se-ia igualmente juntar a "teoria das concepções do mundo" de Dilthey e a "teoria das formas de cultura de Splenger" (NUNES, 1976, p. 75). Entretanto, saindo do âmbito mais geral e indo para um campo mais específico, depois de indicar a importância de "Kant e o problema da metafísica", Nunes sintetiza a importância desse texto para compreendermos a arqueologia de Foucault:

A questão que Kant levantou, nos limites da Ciência da Natureza do século XVIII e graças à crítica da experiência feita por Hume foi, sem dúvida, a questão dos juízos sintéticos a priori. Mas o desenvolvimento desse problema chegaria, ainda dentro do pensamento kantiano, a fixar-se na oposição irremediável entre o homem e a natureza, que permitiu conceber o sujeito humano como 'doublet empirique transcendental', ser natural e empírico por um lado, e ser moral e transcendental por outro. Estaria assim aberto o caminho que, passando por Husserl, vai de Kant a Heidegger, e ao longo do qual a analítica do conhecimento se transformaria na analítica da finitude ou da existência. Em Foucault a analítica da finitude integrará a arqueologia das ciências humanas" (NUNES, p. 75-76).

2 Ver por exemplo a respeito Goris (2014); Spaak (2014) e Rogove (2014). 
Se aqui fiz o percurso cronologicamente inverso, ou seja, expus inicialmente a interpretação de Roberto Machado, elaborada em dois livros tão distantes um do outro, na tese de doutorado publicada em 1982 e no livro posterior de 2000 foi para mostrar, de início, o quanto a interpretação de Benedito Nunes acerca da presença de Heidegger em As palavras e as coisas era correta. Por outro lado, entretanto, a interpretação de Machado já não parte, como é conhecido, de uma insistência em tornar a Fenomenologia, em especial na sua versão heideggeriana, como a grande filosofia que teria antecipado a arqueologia de Foucault e sedimentado o caminho que este seguiu. Ao contrário, Machado procede a partir da confrontação de Foucault com a epistemologia francesa de Bachelard e Canguilhem no livro de 1982 e no livro de 2000, mesmo mantendo o ponto de partida de sua interpretação na crítica de Foucault à epistemologia ele acrescenta o nome de Nietzsche. ${ }^{3}$

Dessa perspectiva, podemos dizer que Roberto Machado segue mais de perto a interpretação foucaultiana, mantendo-se no nível da análise de uma fonte de Foucault - o texto de Heidegger sobre Kant - enquanto em Benedito Nunes a interpretação foucaultiana é remetida para além do texto de Heidegger sobre Kant, para incluir a arqueologia foucaultiana como uma espécie de variante, nem sempre fiel, do projeto fenomenológico. De todo modo, resta ainda acrescentar que o próprio Foucault, em diversas ocasiões, declarou a importância de Heidegger, chegando até mesmo a afirmar, corroborando Benedito Nunes, que Heidegger teria sido a sua maior influência: "Heidegger foi sempre para mim o filósofo essencial (...) Todo o meu devir filosófico foi determinado por minha leitura de Heidegger" embora acrescente imediatamente:

Mas, reconheço que foi Nietzsche que me arrebatou (...). Meu conhecimento de Nietzsche é bem melhor do que o que tenho de Heidegger; mas resta que ambos foram as duas experiências fundamentais que fiz. É provável, que se não tivesse lido Heidegger, não teria lido Nietzsche. Tentei ler Nietzsche nos anos cinquenta, mas Nietzsche sozinho não me dizia nada! Enquanto Nietzsche e Heidegger, isso sim foi um choque filosófico" (FOUCAULT, 1994, p. 703).

Como vimos, mesmo unindo Nietzsche e Heidegger, Foucault não conseguiu impedir que Machado e Nunes seguissem direções opostas. Aquele, por privilegiar Nietzsche, este, Heidegger. ${ }^{4}$

Podemos imaginar que o encontro de Benedito Nunes com Michel Foucault em junho de 1973, o fez lembrar dessa sua leitura de As palavras e as coisas e do profundo impacto que ela Ihe provocou. De tal modo que, quando confirmada alguns meses antes a vinda de Foucault a Belém para novembro de 1976, Benedito Nunes reuniu o pequeno grupo de professores da Faculdade de Filosofia, para ministrar um curso introdutório à filosofia de Foucault. Mesmo já conhecendo os livros posteriores de Foucault, em especial Vigiar e Punir, Benedito Nunes ministrou um curso exclusivamente sobre As palavras e as coisas. Em 1976, dez anos depois de sua publicação e quando a filosofia de Foucault já havia tomado outras direções, para Benedito Nunes As palavras e as coisas ainda continuava sendo "o" livro de Foucault. Na entrevista que concedeu a mim e ao Prof. Marcio Benchimol de Barros, em 2004, mas publicada apenas em 2008, ele reitera sua admiração por esse livro. Quando perguntei a ele qual o legado de Foucault à posteridade, ele respondeu: "Les mots et les choses e o livro sobre o sexo". Referindo-se a Les

\footnotetext{
3 Ver especialmente a respeito o capítulo "A loucura", no qual Machado retoma as linhas gerais da explicitação do projeto arqueológico de Foucault, exposta no livro de 1982 (MACHADO, 2000, p. 15-52) ou ainda passagens de Impressões de Michel Foucault (FOUCAULT, 2017, p. 28-29).

${ }^{4}$ Roberto Machado, entretanto, sempre desconfiou da "sinceridade" de Foucault nas suas entrevistas e por isso afirma nunca ter utilizado demais "seus ditos e pequenos escritos" (MACHADO, 2017, p. 49).
} 
mots et les choses, dirá, destacando, mais uma vez, o que já havia mostrado no artigo de 1968: "É muito importante o fato de ele ter firmado uma noção de positividade, como marca de cada época, com seu regime de pensamento, que é ao mesmo tempo regime de linguagem. Isso me parece uma contribuição muito grande" (NUNES, 2008, p. 22).

Entretanto, a vinda de Foucault ao Brasil em 1976, um ano depois de ter interrompido seu curso na Universidade de São Paulo, ao se solidarizar com os estudantes daquela instituição, que estavam em greve para protestar contra a ditatura militar, representava para Foucault, um desafio. ${ }^{5}$ Logo após sua adesão à greve dos estudantes e sua presença no ato ecumênico realizado na Catedral de São Paulo para lembrar o sétimo dia da morte do jornalista Vladmir Herzog em 25 de outubro de 1975, numa conhecida prisão paulista onde prisioneiros políticos eram interrogados, torturados e, por vezes, mortos, foi expedida uma ordem de prisão contra Foucault, que não se realizou pelo temor da repercussão negativa nacional e internacional, que isso ocasionaria. ${ }^{6}$

Mesmo não sabendo ainda de todos esses detalhes, Benedito Nunes sabia muito bem que em nossa universidade havia agentes infiltrados, alunos que eram, na verdade, policiais dos órgãos de segurança. Penso que ele organizou uma lista de convidados para as palestras de Foucault, para evitar os "infiltrados". Da mesma forma, combinou com Foucault que ele faria as conferências sem tradução e que só o debate seria traduzido. Todas essas medidas foram tomadas e devemos ao prestígio de Benedito Nunes, o fato de que elas foram cumpridas à risca. Não houve nenhuma interferência na organização das conferências, que ficaram inteiramente a cargo dele. No fundo, ele queria "blindar" Foucault, como dizemos hoje, ele queria salvaguardá-lo ao máximo de qualquer problema político. E quando nos dias posteriores às conferências, Benedito Nunes foi inquirido pelos órgãos de segurança para entregar a lista dos presentes às conferências ele não só se recusou a entregá-la, como também a destruiu. É importante sempre lembrar desses pequenos grandes gestos de Benedito Nunes, para resistir às apropriações conservadoras que teimam em fazer de sua pessoa e de sua obra.

Gostaria de finalizar devolvendo a palavra a Benedito Nunes para mostrar a presença de As palavras e as coisas em dois momentos diferentes de sua obra e posteriores a essa sua primeira consideração a propósito de Foucault.

O primeiro se encontra em um artigo de 1976, publicado inicialmente na série "Letras e Artes" dos Cadernos da PUC-RJ, a mesma série na qual as conferências de Foucault naquela mesma instituição, em maio de 1973, hoje as famosas conferências sobre "A verdade e as formas jurídicas". O artigo de Benedito Nunes a propósito de Guimarães Rosa se chama "Literatura e Filosofia (Grande sertão: veredas)". Ao discutir a relação entre poesia/literatura e filosofia, na seção 2 do "Prólogo não muito curto", Benedito Nunes se utiliza de As palavras e as coisas para marcar, juntamente com episteme moderna o aparecimento da literatura (grifos dele). Vale a pena reproduzir esse parágrafo porque nele reencontramos a argumentação do artigo de 1968, só que, desta feita, sem polemizar com Foucault, reconhece de bom grado sua contribuição para o entendimento do lugar e da função da literatura na nossa modernidade, mesmo que só como ponto de partida:

Com a partilha do saber na Idade Moderna, depois da época clássica, verifica-se, ao mesmo tempo que o aparecimento da literatura - "isolamento de uma linguagem singular, cuja modalidade própria é ser literária" - da qual nos fala Foucault, a organização das ciências

\footnotetext{
5 Ver a respeito Marques Neto $(2017$, p. 21-23).

6 Ver a respeito Rodrigues (2016), inclusive pelo acesso que dá ao leitor aos documentos que compunham a pasta "Michel Foucault" no DOPS, o famigerado Departamento de Ordem Política e Social.
} 
humanas. Abrir-se-á já no ciclo da metafísica em crise - pela primeira vez posta globalmente em questão na Crítica da razão pura (1781) - e da filosofia colocada em face de sua originária historicidade - o perpétuo debate entre o conhecimento filosófico e as ciências humanas, estas reivindicando, 'como seu objeto próprio, aquele que teria antes constituído o domínio da filosofia' (NUNES, 2013, p. 142).

A segunda referência se encontra nas duas últimas edições de seu livro Filosofia contemporânea. A partir da terceira edição do livro, de 2004, pela Editora da UFPA (a 1 a edição, é de 1967, na Coleção "Buriti" da EDUSP, a 2a edição, pela Editora Ática é de 199, enquanto a $4^{a}$ edição, de 2019, também pela EDUFPA), Benedito Nunes acrescentou duas secções sobre Foucault. A primeira, intitulada "Arqueologia e Hermenêutica" e a segunda "Genealogia do Saber". "Arqueologia e Hermenêutica" se abre, como não poderia deixar de ser, com As palavras e as coisas:

O primeiro grande projeto de topologia desse domínio do conhecimento, como história diferencial, delineia-se na arqueologia de Michel Foucault desde Les mots et les choses. 'O que possibilita as ciências humanas?'é a pergunta kantiana dessa obra pioneira. A resposta que ela dá é que tal possibilidade se encontra fora das disciplinas e da função do sujeito transcendental, num a priori histórico, a episteme da época moderna, que articulou, abrindo espaço para a Biologia, a Economia e a Linguística, uma constelação de conceitos favoráveis ao estranho conhecimento do homem - estranho porque conhecimento de uma realidade privilegiada e invasora, capaz de originar o tipo de positividade fraca, anômala, persistente e desdobrável das ciências humanas. Conceitualizado e teorizado, o homem passou a existir como objeto de discurso. Hermenêutica complexa a "arqueologia" de Foucault, que transfere a filosofia crítica moderna, o pensamento de Kant, revisto por Husserl e Heidegger, a posição de interpretante! Pois o homem, como objeto de discurso, funda, ao mesmo tempo sem reduzir-se a objeto empírico, na qualidade de sujeito transcendental, o conhecimento acerca de si mesmo" (NUNES, 2019, p. 197).

Como se vê, Benedito Nunes manteve-se fiel ao princípio que norteava sua interpretação de As palavras e as coisas desde o artigo de 1968: no artigo sobre Guimarães Rosa, ele retoma a questão da episteme, lembrando que para Foucault a "literatura" surge apenas na modernidade em consonância com o aparecimento das ciências humanas, na esteira de Kant e de sua releitura por Heidegger, os se trata de coloca a filosofia "em face de sua originária historicidade"; no capítulo introduzido no livro bem antigo, da década de 1970, ele insere Foucault, mais uma vez, na tradição que ele mais apreciou, ou seja, a da fenomenologia de Husserl e Heidegger, cujo começo é inevitavelmente Kant.

O fato de que seu jovem aluno, o autor dessas mal traçadas linhas e que começou a estudar Foucault por indicação dele, não tenha seguido essa mesma linha interpretativa mostra a face do mestre par excellence que foi Benedito Nunes, qual seja, a de permitir que seus alunos pudessem encontrar seus próprios caminhos. O recente falecimento de Roberto Machado, com quem Benedito Nunes foi ligado por profundos laços de amizade - Roberto Machado veio diversas vezes a Belém, entre 1982 e 2009, sempre a convite de Benedito Nunes, para cursos e palestras - me lembrou mais uma vez o quanto para Benedito Nunes a amizade e o respeito pelos que pensavam diferente dele sempre foi uma marca de sua figura humana e de seu trabalho de pensamento.

\section{Referências}

CHAVES, L. S. (Org.). O amigo Bené, fazedor de rumos. Belém: SECULT, 2011.

ERIBON, D. Michel Foucault. Édition revue et enrichie. Paris: Flamarion, 2011. 
FOUCAULT, M. As palavras e as coisas. Tradução de Salma Tannus Muchail. São Paulo: Martins Fontes, 1981.

FOUCAULT, M. A verdade e as formas jurídicas. 3ª ed. Rio de Janeiro: Nau Editora, 2002.

FOUCAULT, M. “Le retour de la morale”. In: Dits et écrits. Vol. IV. Paris: Galimmard, 1994.

GORIS, W. “L'a priori historique chez Husserl et Foucault”. Philosophie, n. 123, été 2014.

HEIDEGGER, M. Kant y el problema de la metafisica. Mexico DF: Fondo de cultura econômica, 1996.

LÉBRUN, G. "Transgredir a finitude". In: JANINE RIBEIRO, R. (Org.). Recordar Foucault. São Paulo: Brasiliense, 1985.

MACHADO, R. Ciência e saber. A trajetória da arqueologia de Foucault. Rio de Janeiro: Graal, 1982.

MACHADO, R. Foucault, a filosofia e a literatura. Rio de Janeiro: Jorge Zahar Editor, 2000.

MACHADO, R. Impressões de Michel Foucault. São Paulo: n_1 Edições, 2017.

MARQUES NETO, J. C. “No táxi com Michel Foucault. Memórias de um estudante de filosofia aos 22 anos". Revista Cult, n. 225, jul/2017.

NUNES, B. "Apresentação". In: CHAVES, E. Foucault e a psicanálise. Rio de Janeiro: Forense Universitária, 1988.

NUNES, B. “Entrevista”. Trans/form/ação. Marília, n. 31, p. 9-23, 2008.

NUNES, B. Filosofia Contemporânea. 4ª ed. Belém: EUFPA, 2019.

NUNES, B. “Literatura e filosofia (Grande sertão: Veredas)". In: A Rosa o que é de Rosa. Literatura e Filosofia em Guimarães Rosa. Rio de Janeiro, DIFEL, 2013.

NUNES, B. O dorso do tigre. 2a ed. São Paulo: Perspectiva, 1976.

RODRIGUES, H. de B.C. Ensaios sobre Michel Foucault no Brasil. Presença, efeitos, ressonâncias. Rio de Janeiro: Lamparina Edições/FAPERJ, 2016.

ROGOVE, J. "La phenomenologie manquée de Foucault: Husserl et le contre-modèle de I'anthropologisme kantien". Philosophie. n. 123, été 2014.

SPAAK, C. V. "L'être de I'homme à travers limites et finitude: Foucault et la critique de l'ontologie heideggérienne". Philosophie. n. 123, été 2014.

\section{Sobre o autor}

\section{Ernani Chaves}

Doutor em Filosofia (USP, 1993). Professor Titular da Faculdade de Filosofia da UFPA. Áreas de pesquisa: os pensamentos de Foucault, Nietzsche, Walter Benjamin, assim como as relações entre Filosofia e Psicanálise. 